\title{
Megarrecto y anismo: causa de estreñimiento
}

\author{
Y. Real Martínez, M. Ibáñez Moyaํy A. Pérez Mota \\ Servicio de Aparato Digestivo y 'Radiodiagnóstico. Hospital Virgen de la Torre. Madrid
}

Varón de 17 años que consulta por presentar estreñimiento pertinaz desde la infancia, coincidiendo con el inicio del control de esfínteres. Realizaba deposiciones duras y escasas cada 10-15 días, en muchos casos inducidas por el uso de supositorios o enemas de limpieza. A veces se asociaba con dolor abdominal cólico de localización baja y en los últimos meses había comenzado con emisión esporádica de heces semisólidas por rebosamiento. No refería enfermedades previas, ni tratamientos concomitantes.

Se realizó estudio radiológico baritado de colon mostrando una marcada dilatación de ampolla rectal y recto hasta sigma donde se aprecia un área de disminución de calibre de bordes lisos que podría corresponder a un área de transición puesto que, a partir de aquí, se observa un colon que conserva el calibre y los haustras (Figs. 1 y 2). No se consigue la progresión del bario más allá de ángulo esplénico por aumento de la dilatación rectal.

Se sometió a una colonoscopia completa donde se observa una mucosa de colon de aspecto normal con marcada dilatación hasta $30 \mathrm{~cm}$ de ano sin peristalsis visible, y sin zonas de estenosis. Se tomaron biopsias de la zona dilatada informada como mucosa de recto-sigma con proceso inflamatorio crónico carente de signos histológicos de especificidad. Ante estos hallazgos y para descartar la posibilidad de una enfermedad de Hirschprung se realizó una manometría anal donde se encontró discreta hipotonía del conducto anal (P. de reposo entre 38 y $61 \mathrm{mmHg}$ ) con ausencia de respuesta refleja a la distensión. Se completó el estudio con la realización de un barostato rectal donde tras el llenado de un balón rectal se desencadena la presencia de un reflejo recto anal inhibitorio a $4 \mathrm{mmHg}$ (normal) con sensibilidad a la distensión rectal den-

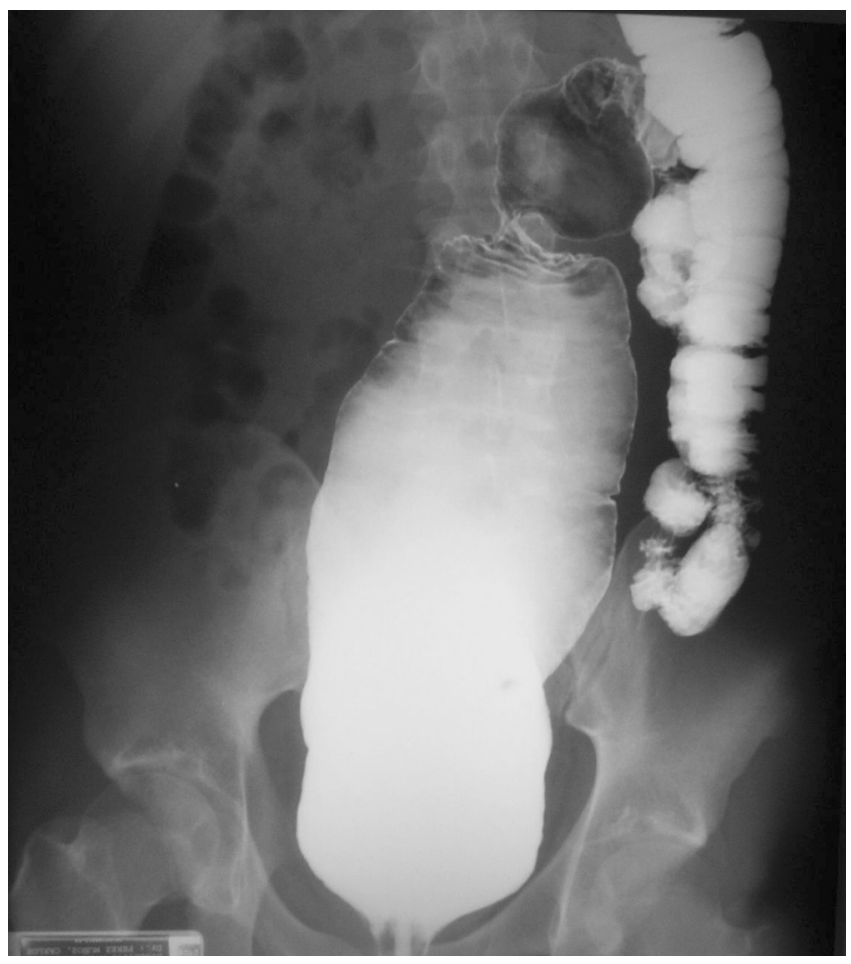

Fig. 1. Estudio baritado de colon donde se muestra la importante dilatación rectal y sigmoidea con mucosa aparentemente normal y área estenótica proximal que parece corresponder con espasmo colónico.

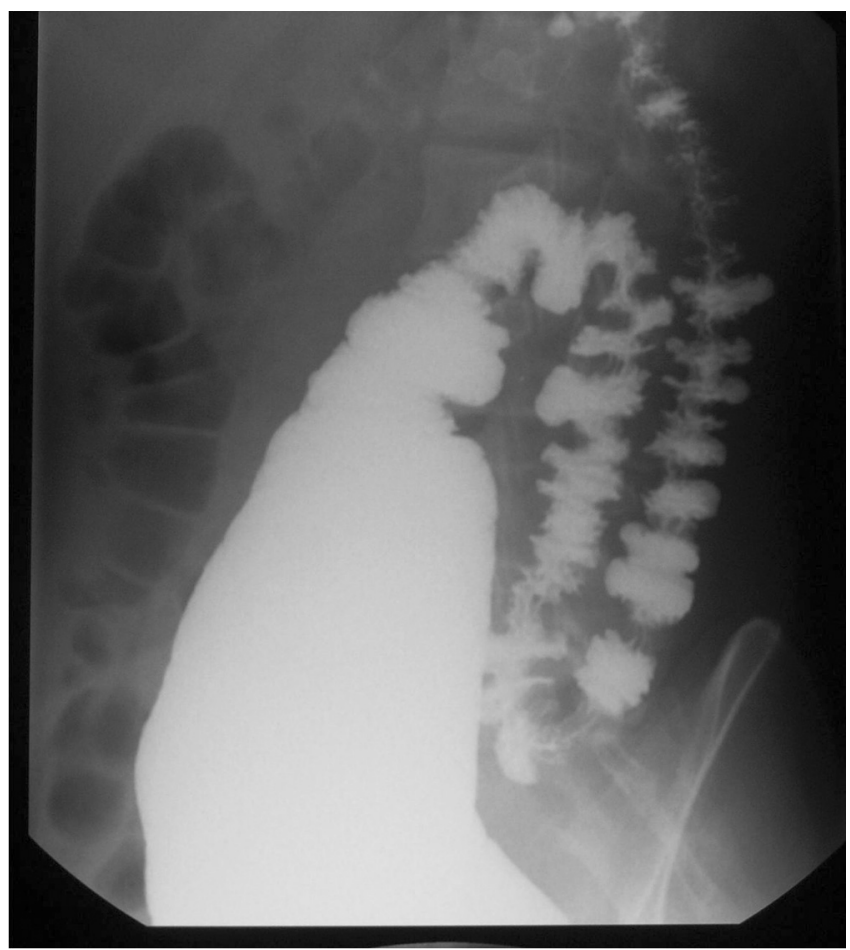

Fig. 2. Tras la introducción de mayor cantidad de contraste desaparece el área estenótica descrita en la figura previa. 
tro de la normalidad (umbral de urgencia a $8 \mathrm{mmHg}$ ) y compliance rectal aumentada $(20 \mathrm{ml} / \mathrm{mmHg}$ ). Durante la maniobra defecatoria se produjo una adecuada prensa abdominal acompañada de una contracción inadecuada del esfínter anal lo cual lo hace compatible con anismo.

Tras esto se inició tratamiento con laxantes osmóticos y estimulantes así como reeducación del hábito defecatorio obteniendo una escasa respuesta, por lo que se remite al paciente a una Unidad de Proctología para realización de biofeedback.

El anismo o defecación obstructiva sin alteración anatómica se debe a un fallo en la relajación o a una contracción paradójica de la musculatura estriada esfinteriana y del suelo pelviano durante la defecación (1). El mecanismo por el cual se produce el estreñimiento es un fallo para rectificar el ángulo anorrectal y para acortar el canal anal por la contracción mantenida del músculo puborrectal.

Un 50\% de los pacientes con estreñimiento crónico funcional referidos a centros terciarios presentan obstrucción en la defecación (anismo, disinergia del suelo pelviano o dismotilidad anorrectal). Suelen mostrar un tiempo de transito colónico normal con retraso en el tránsito del segmento rectosigmoideo (2). Algunos de estos pacientes presentan una alteración anatómica responsable como megarrecto, rectocele, enterocele, etc., o simplemente una alteración funcional con espasmo de los músculos del suelo pélvico resultando en una resistencia a la defecación (anismo) (3). En nuestro caso el paciente presentaba tanto anismo como megarrecto posiblemente secundario a la obstrucción anal de larga evolución, que condicionaría un tránsito lento de las heces en ese segmento empeorando aún más la función defecatoria. Aunque no existe ninguna prueba funcional específica para realizar el diagnóstico de anismo, con frecuentes falsos positivos, en este caso la asociación del cuadro clínico junto con los hallazgos radiológicos y especialmente del barostato rectal hacen muy probable este diagnóstico. Siendo lo más llamativo del mismo la larga evolución hasta el diagnóstico y la marcada dilatación rectal asociada. El tratamiento óptimo del anismo suele ser el biofeedback que mejora subjetiva y objetivamente la función anorrectal en el 60-80\% de los pacientes (4). Se encuentran en fase de desarrollo estudios de la inyección de toxina botulínica en el músculo puborrectal con resultados por definir (5).

\section{AGRADECIMIENTOS}

Nuestro agradecimiento a la Unidad de motilidad del Hospital Clínico San Carlos por su colaboración en el caso.

\section{BIBLIOGRAFÍA}

1. García-Armengol J, Moro D, Ruiz MD, et al. Defecación obstructiva. Métodos diagnósticos y tratamiento. Cir Esp 2005; 78 (Supl. 3): 59-65.

2. Pettica L, Pescatori M. Outlet obstrucción due to anismus and rectal hyposensation: effect of bioefeedback training. Colorectal Disease 2002; 4 (1): 67.

3. Andromanakos N, Skandalakis P, Troupis T, Filippou D. Constipation of anorectal outlet obstruction: Pathophysiology, evaluation and management. J Gastroent Hepatol 2006; 21 (4): 638-46.

4. Fernández-Fraga X, Azpiroz F, Casaus M, Aparici A, Malagelada JR. Responses of anal constipation to biofeedback treatment. Scand J Gastroenterol 2005; 40: 20-7.

5. Friedenberg F, Gollamudi S, Parkman HP. The use of botulinum toxin for the treatment of gastrointestinal motility disorders. Dig Dis Sci 2004; (2): 165-75. 